\title{
¿Equidad o tradición?: La participación política de mujeres comuneras en procesos de consulta previa
}

\author{
Alexia Potesta Cortez \\ Estudiante de Antropología en la Pontificia Universidad Católica del Perú (PUCP). \\ e-mail: a20160072@pucp.edu.pe
}

\section{Resumen}

El presente ensayo tiene como finalidad revisar las referencias normativas del proceso de consulta previa, subrayar los vacíos legales presentes en la aplicación del enfoque de género y analizar los factores que debilitan la participación de mujeres comuneras peruanas en dicho proceso. A través de la revisión de referencias legales y investigaciones académicas, se abordará de manera cualitativa la situación política de las mujeres comuneras y se describirán las trabas para su participación en la esfera pública. Estas nociones nos aproximan a reflexionar sobre necesidad de renovación de estatutos y normativas gubernamentales, y del diseño de metodologías interculturales que garanticen la paridad en los procesos. Finalmente, el artículo propone cuestionarnos si la consulta previa, en la práctica, contribuye a reforzar las estructuras de poder y de género consuetudinarias y en qué medida sus referencias legales desalientan la participación de mujeres comuneras.

\section{Palabras clave}

Consulta previa, enfoque de género, comunidades campesinas, mujeres comuneras, derecho consuetudinario, equidad. 


\title{
Equity or tradition?: Community women's political participation in prior consultation processes
}

\author{
Alexia Potesta Cortez \\ Anthropology student at the Pontifical Catholic University of Peru (PUCP). \\ e-mail: a20160072@pucp.edu.pe
}

\begin{abstract}
The purpose of this essay is to review the normative references of the prior consultation process, highlight the legal gaps in the the gender approach application and analyze the factors that weaken the participation of peruvian community women in the process. The political situation of community women will be addressed qualitatively and the obstacles to their participation in the public sphere will be described through the review of legal references and academic research, . These notions reflect the need for a government statutes and regulations renewal, and the design of intercultural methodologies that guarantee parity in the processes. Finally, the article questions whether prior consultation, in the practice, contributes to reinforcing customary power and gender structures and, in what extent its legal references discourage the participation of community women.
\end{abstract}

\section{Keywords}

Prior consultation, gender approach, peasant communities, community women, customary law, equity. 


\section{Introducción}

Las cifras de participación de mujeres comuneras de los 42 procesos de consulta previa realizados en el Perú hasta el 2017 (CAAAP, 2017, p. 7) delatan la urgencia de reformular las referencias normativas relacionadas a la aplicación del enfoque de género en el proceso de consulta previa y de implementar medidas interculturales que logren conciliar los derechos individuales de las mujeres y los derechos colectivos de las comunidades campesinas. Para que una comunidad reciba el derecho a la consulta previa es un requisito previo que la comunidad sea reconocida como indígena y originaria, $\mathrm{y}$, consiguientemente, que la comunidad conserve ciertos usos y tradiciones. La Ley N $\mathrm{N}^{\mathrm{0}}$ 29785, Ley del Derecho a la Consulta Previa, ratifica que los procesos de consulta deberán realizarse respetando estos derechos consuetudinarios. Dicha ley dice, también, garantizar la participación de la mujer comunera mediante un enfoque de género, pero con la condición de no interferir con los usos y tradiciones de la comunidad. En la práctica, estas referencias normativas resultan un factor debilitante de la participación de mujeres comuneras en las tareas de participación política, en tanto las prácticas políticas consuetudinarias responden a roles de género que, muchas veces, no consideran a las mujeres como comuneras calificadas para la participación. Teniendo en cuenta lo anterior, el presente artículo tiene como objetivo analizar los diversos factores que debilitan la participación política de mujeres comuneras en los procesos de consulta previa. Finalmente, abre un debate sobre cómo empoderar a la mujer en el ámbito público comunal si, en la realidad, las referencias normativas para la aplicación de la consulta previa refuerzan las estructuras de género consuetudinarias.

\section{Marco teórico}

Para el presente artículo, el enfoque de género constituye una herramienta conceptual central para abordar los niveles de paridad en espacios de negociación, así como para comprender las ontologías inscritas en los roles y estructuras de género que rigen la propiedad de la tierra y la división sexual del trabajo. De acuerdo a Rita Bórquez, la perspectiva de género tiene como punto de partida "el reconocimiento de la subordinación social y política de las mujeres", en el marco de un debate teórico sobre "el poder, la identidad y la estructuración de la vida social" (p. 63 en CEPES, 2011). Respecto al género en sí, este será entendido como una "una categoría construida socialmente para definir lo masculino y femenino" que tiene el potencial de significar las relaciones de poder (Pinzás, 1997, en Urrutia, 2007, p. 260). Estas relaciones de poder se reflejan en los roles de género, entendidos como prácticas y comportamientos aprendidos que asignan las actividades consideradas apropiadas para lo femenino y para lo masculino (Urrutia, 2007, p. 260). En este sentido, una manera de conseguir la equidad de género es modificando las relaciones de poder imbricadas en las relaciones de género, lo que significaría aumentar la cuota de poder, negociación y representación de las mujeres en la esfera privada y pública, aspecto que puede ser entendido como empoderamiento. 
Para comprender de qué manera el empoderamiento de mujeres comuneras se ve obstaculizado, es necesario hace referencia a los tipos de derechos que poseen las comunidades campesinas como colectivo y los derechos que poseen las mujeres indígenas como individuos. La Constitución Política de 1993 otorga a los pueblos indígenas u originarios un estatus jurídico y un "marco legal propio que les permite gozar de derechos colectivos" reconocidos en la Declaración de las Naciones Unidas sobre los Derechos de los Pueblos Indígenas (Ministerio de Cultura, 2016, p. 8). Las mujeres indígenas como individuos, por su parte, son receptoras de derechos particulares avalados por la Convención Sobre la Eliminación de Todas las Formas de Discriminación Contra la Mujer, ratificada por el Estado Peruano en 1979. Esta Convención compromete al Estado a "eliminar la discriminación contra la mujer en la vida política y pública del país" y garantiza la igualdad de condiciones en el derecho a "participar en organizaciones y en asociaciones no gubernamentales que se ocupen de la vida pública y política del país"2 (Ministerio de Justicia, 2014, p. 4). Como se observará en el desarrollo del presente artículo, esta referencia legal en defensa de los derechos individuales de las mujeres indígenas no es del todo compatible con los derechos colectivos de las comunidades campesinas.

\section{Metodología}

Luego, para la elaboración de este artículo, me enfocaré en cuatro ejes de análisis. En primer lugar, expondré los vacíos legales dentro de la normativa peruana de la consulta previa, con énfasis en la aplicación deficiente del enfoque de género. En segundo lugar, explicaré de qué manera las estructuras políticas y de género consuetudinarias en las comunidades campesinas conforman un conjunto de trabas en la participación efectiva de las mujeres. En tercer lugar, identificaré las deficiencias en la regulación estatal y las entidades técnicas que no logran garantizar la equidad y paridad en los procesos de consulta. Y, por último, abordaré las discusiones en torno a cómo defender los derechos individuales de las mujeres a la equidad frente a los derechos colectivos y consuetudinarios de las comunidades campesinas.

La información recogida sobre los derechos colectivos de las comunidades campesinas y pueblos indígenas $\mathrm{u}$ originarios provienen de los documentos de la Ley General de Comunidades Campesinas, el Convenio № 169 de la Organización Internacional del Trabajo sobre Pueblos Indígenas y Tribales, la Ley $N^{\circ} 24565$ del Derecho a la Consulta Previa a los Pueblos Indígenas u Originario y el Reglamento para la Aplicación de la Ley No 29785, Ley del Derecho a la Consulta Previa. Y la información sobre los derechos individuales de las mujeres comuneras provienen de las mismas fuentes, con excepción de la Ley General de Comunidades Campesinas, (que no hace referencia alguna al enfoque de género o a los derechos de mujeres

1 Artículo 7.

2 Artículo 7, inciso c. 
comuneras) y el documento de la Convención Sobre la Eliminación de Todas las Formas de Discriminación Contra la Mujer³ ${ }^{3}$ Las información sobre la situación actual de la participación de mujeres comuneras proviene informes e investigaciones realizadas por la Organización Nacional de Mujeres Indígenas Andinas y Amazónicas del Perú (ONAMIAP), la Coordinadora Nacional de Derechos Humanos y otros.

Sin embargo, es necesario subrayar que la información sobre las relaciones de género en comunidades campesinas es escasa, pues "la mayoría de investigaciones remite a la problemática de «la mujer rural» o «la mujer campesina», sin considerar las particularidades que otorga a ambas categorías el hecho de ser «mujer comunera»" (Urrutia, 2007, p. 283). Asimismo, los trabajos especializados sobre la distribución familiar de la tierra dentro de las comunidades y sobre la "distribución de la propiedad y usufructo entre mujeres casi no existen (las pocas referencias indicarían que las mujeres tienen un limitado acceso a la tierra)" (Diez, p. 86, en CEPES, 2011).

\section{Referencias normativas y vacíos legales}

En el 2010, el pleno del Congreso peruano aprobó la Ley N² 29785, Ley del Derecho a la Consulta Previa a los Pueblos Indígenas u Originarios, 15 años después de la suscripción del Estado peruano al Convenio $N^{\circ} 169$ de la Organización Nacional del Trabajo. Esta norma estipula que "es el derecho de los pueblos indígenas u originarios a ser consultados de forma previa sobre las medidas legislativas o administrativas que afecten directamente sus derechos colectivos, sobre su existencia física, identidad cultural, calidad de vida o desarrollo"4 con la finalidad de "alcanzar un acuerdo o consentimiento entre el Estado y los pueblos indígenas u originarios respecto a la medida legislativa o administrativa que les afecten directamente, a través de un diálogo intercultural que garantice su inclusión en los procesos de toma de decisión del Estado"5 (Congreso de la República, 2019, p. 1).

Una condición para que las comunidades campesinas logren tener el derecho a la consulta previa es que sean reconocidos como pueblos indígenas u originarios $\mathrm{y}$, entre las condiciones para ser reconocido como tal, está el conservar "todas sus propias instituciones sociales, económicas, culturales y políticas, o parte de ellas" (OIT, 2014, p. 20). Para ello, la forma de participación comunal queda formulada de antemano en el Artículo 6 de la Ley $N^{0}$ 29785, que contempla que los pueblos indígenas u originarios participarán "a través de sus instituciones y organizaciones representativas, elegidas conforme a sus usos y costumbres tradicionales" (Congreso de la República, 2019, p. 2).

\footnotetext{
Puesta en vigor en 1981.

4 Artículo 2.

5 Artículo 3.
} 
En el Reglamento de la Ley N ${ }^{\circ} 29785$, publicado en el 2012, se hace mención al "especial interés a la situación de las mujeres" a efectos de conseguir un "verdadero diálogo intercultural"6 (El Peruano, 2012, p. 4). Asimismo, destaca que el proceso de consulta se realizará "a través de una metodología con enfoque intercultural, de género, participativo y flexible a las circunstancias"7 (El Peruano, 2012, p. 5). Sin embargo, a pesar de este "especial interés", se estipula lo siguiente:

h) El proceso de consulta debe realizarse respetando los usos y tradiciones de los pueblos indígenas, en el marco de lo establecido por la Constitución y las leyes. La participación de las mujeres, en particular en funciones de representación, se realizará conforme a lo señalado en este inciso ${ }^{8}$ (El Peruano, 2012, p. 4)

Por un lado, el Reglamento de la Ley $\mathrm{N}^{0} 29785$ recalca la necesidad de que los procedimientos de decisión o elección en el proceso de consulta se realicen "en un marco de plena autonomía, y sin interferencia de terceros ajenos a dichos pueblos, respetando la voluntad colectiva" (El Peruano, 2012, p. 4). Sin embargo, como se observa en el Inciso "h", el respeto por la autonomía política de los pueblos indígenas entra en conflicto con la aplicación de una metodología con enfoque de género, en tanto la participación de las mujeres queda condicionada a los usos y tradiciones, cuyas estructuras de poder, en la práctica, no reflejan una representación paritaria.

Desde la aprobación de la Ley N² 29785, en el 2011 hasta el 2017, se han implementado 42 procesos de consulta previa, de los cuales 34 han sido concluidos y ocho siguen en marcha ${ }^{10}$ (CAAAP, 2017, p. 7). Del total de procesos, sólo 20 cuentan con cifras de la participación de mujeres y estas revelan que 6 procesos tuvieron nula participación de mujeres; mientras que, en 9 procesos, el número de mujeres representantes oscila entre 1 y 4 mujeres, cuando -en los mismos- son entre 8 y 18 varones (CAAAP, 2017). En 17 de 27 casos de consulta analizados por la ONAMIAP, los registros están incompletos, no hay listados como medios de verificación, los registros son ilegibles y no permiten la identificación de los participantes (ONAMIAP, 2019, p. 42). A pesar de que las cifras podrían "aportar bases sólidas para la formulación y aplicación de políticas y contribuir a que las propias organizaciones indígenas vigilen las acciones que emprende el Estado", actualmente no existen herramientas e instrumentos para obtener registros efectivos de la asistencia a los procesos de consulta (CEPAL, 2014, p. 9).

Teniendo en cuenta estas condiciones, es importante indagar cómo las comunidades campesinas interpretan estas referencias legales, en la medida que propician la

\footnotetext{
Título III, Artículo 5, Inciso g.

Artículo 13.

8 Título III, Artículo 5, Inciso h.

9 Título II, Artículo 5, Inciso i.

10 Cifras del 2017.
} 
perpetuación de estructuras políticas consuetudinarias, donde las relaciones de género resultan jerárquicas y desalentadoras para la participación política de la mujer comunera.

\section{Estructuras de poder $y$ de género en las comunidades campesinas}

A pesar de las limitaciones en la información y, a partir de las cifras disponibles de la participación de mujeres, cabe cuestionarnos si este instrumento de desarrollo de las comunidades campesinas está sirviendo para empoderar, desde la paridad, a la mujer comunera como individuo y sujeto de derechos, o si más bien es un proceso que acentúa y reproduce los roles de género tradicionales (Hoyos y Valencia, 2017, p. 4). Una aproximación al funcionamiento de los sistemas políticos y de género de las comunidades campesinas puede alumbrar esta interrogante. De acuerdo con Rita Bórquez, los roles de género en las comunidades consideran a la mujer comunera en América Latina como un "sujeto dependiente, no productivo, y su trabajo es visto como «ayuda» no económica" (Bórquez p. 64 en CEPES, 2011). La división sexual del trabajo se expresa en la "concentración de las mujeres en tareas de reproducción en el ámbito doméstico y también en determinadas actividades y puestos dentro del trabajo remunerado" (Bórquez, p. 64, en CEPES, 2011); mientras que los hombres se ubican en el ámbito productivo, en el mercado y el espacio extra doméstico (Bórquez en CEPES, 2011). "En el espacio comunal, su rol está restringido, por lo general, a las actividades asistenciales. Sus oportunidades de participación y acceso a la toma de decisiones dependen de las estructuras de la comunidad y su organización, y todo está supeditado a la voluntad de la dirigencia que usualmente es masculina" (ONAMIAP, 2019, p. 15). Excepcionalmente, algunas mujeres acceden a los cargos de secretaria, tesorera o vocal, pero siempre con la autorización del esposo, en tanto se les considera honestas y honradas para guardar dinero, mas no para administrarlo (Asociación Madre Coraje, 2005).

Las instituciones de poder dentro de las comunidades, como la Asamblea Comunal y las delegaciones y cargos políticos comunales están manejados por principios androcéntricos (Belaúnde en CEPES, 2011), hasta el punto que el Censo Agrario del 2013 reveló que el 96.3\% de comunidades campesinas y el 97.7\% de comunidades nativas están presididas por hombres (ONAMIAP, 2016). Y son estos mismos principios androcéntricos los que son avalados por el Artículo n ${ }^{\circ} 6$ de la Ley $\mathrm{N}^{\circ} 29785$, que defiende que la consulta se desarrolle "a través de sus instituciones y organizaciones representativas, elegidas conforme a sus usos y costumbres tradicionales"11 (Congreso de la República, 2019, p. 2).

11 Artículo 6. 
El esposo "representa formalmente a la familia ante la comunidad: está registrado en el padrón comunal, asiste a las asambleas, opina y toma decisiones. Las mujeres asisten solo si son viudas, madres solteras o cuando su esposo está ausente; en general, su opinión no tiene mayor impacto" (Urrutia, 2007, p. 275). Esta jerarquía de género solía entenderse en el ámbito académico a partir de un principio de complementariedad entre lo femenino y lo masculino; es decir, una suerte equilibrio intra familiar por el cual las mujeres participarían indirectamente en los espacios públicos "al poseer capacidad de decisión al interior de la familia, mientras que el hombre canaliza en los espacios públicos estas decisiones (Urrutia, 2007, p. 269). Sin embargo, esta propuesta culturalista ha sido desmitificada por autores como De La Cadena y Scout, que muestran que en el espacio conyugal existen evidencias de jerarquía y diferenciación, y que la mujer comunera carece de poder intra familiar (Urrutia 2007, p. 263).

Si bien es cierto que ninguna legislación peruana impide a las mujeres el acceso a la tierra, "en muchos casos, se trata de un reconocimiento más formal que real, y subsisten fuertes desigualdades en la distribución de recursos económicos" (Diez, p. 85 en CEPES, 2011). Este derecho desaparece ante patrones patriarcales del derecho consuetudinario y del derecho colectivo pues, de acuerdo con las normas consuetudinarias de muchas comunidades, los varones son los comuneros calificados para la tenencia de tierras. El tema del derecho consuetudinario a la tenencia de tierras diferenciada por géneros puede considerarse uno de los factores de la falta de equidad de género, en tanto las condiciones materiales determinan en gran medida la organización social y económica (Bórquez, p. 63, en CEPES, 2011). Urrutia sostiene que una vía para aumentar la capacidad de negociación y representación en los espacios públicos de las mujeres es el incremento de sus condiciones de acceso a la tenencia de la tierra (Urrutia, 2007), pues "para la visión particular de la mujer, constituye una red de protección frente a posibles situaciones de abandono, violencia familiar y pobreza" (Cuadros, p. 222 en CEPES, 2011).

En este punto, es necesario retomar algunos incisos del Reglamento de la Ley $\mathrm{N}^{\mathrm{o}}$ 29785, que precisa que la consulta deberá realizarse prestando "especial interés a la situación de las mujeres" 12 y "a través de una metodología con enfoque intercultural, de género, participativo y flexible a las circunstancias"13 (El Peruano, 2012, p. 5). Sin embargo, esta norma no se condice con la realidad, pues "si bien teóricamente un comunero calificado puede ser hombre o mujer, la práctica consuetudinaria conduce a que solo exista un comunero representante por familia y sea el varón designado como cabeza del hogar y quien lo representa", y que el acceso al título de comunero calificado sea accesible a las mujeres en caso de ser viuda o madre soltera (Urrutia 2007, p. 276). Los requisitos de la Ley General de Comunidades Campesinas para ser

\footnotetext{
12 Título III, Artículo 5, Inciso g.

13 Título III, Artículo 5, Inciso h.
} 
considerado comunero se estipulan todos con un artículo masculino ${ }^{14}$, mientras que la mujer es mencionada únicamente en los requisitos para ser comunera "integrada" 15 (Congreso de la República del Perú, 1992, p. 5).

Para afianzar la situación, la misma Ley General de Comunidades Campesinas restringe sólo a los comuneros calificados "el derecho a elegir y ser elegidos para cargos propios de la comunidad y a participar con voz y voto en las Asambleas Generales"16 (Congreso de la República, 1992, p. 6). Aquí podemos constatar que el reconocimiento del derecho a la consulta previa ha tenido un "fuerte sesgo masculino que, en la práctica, no hace más que responder a las estructuras en las que se han construido las dinámicas políticas de las comunidades" (ONAMIAP, 2016, p. 128). A través de estas limitaciones, en el derecho formal y consuetudinario podemos apreciar las múltiples dimensiones de las barreras que impiden a las mujeres comuneras emprender roles de liderazgo, negociación y participación política en los procesos de consulta.

\section{Deficiencias en la regulación estatal}

Las empresas mineras constituyen un actor económico poderoso que influye en gran medida en las relaciones políticas, sociales y económicas de las comunidades campesinas, de modo que su presencia conlleva un incremento de las desigualdades, asimetrías y la acentuación de brechas sociales, económicas y de género (Cuadros, p. 236 en CEPES, 2011). La tarea de contrarrestar la acentuación de las brechas de género durante los procesos de consulta previa es responsabilidad del Viceministerio de Interculturalidad. Este es el órgano técnico del Ministerio de Cultura que está especializado en pueblos indígenas y responsable de la implementación del derecho a la consulta previa (ONAMIAP, 2016, p. 61) y, de acuerdo con el Reglamento de la Ley N $\mathrm{N}^{\mathrm{2}} 29785$, es la entidad promotora de la "participación efectiva de mujeres" 17 (El Peruano, 2012, p. 5). Esto supone capacidades especializadas, sistemas de verificación, desarrollo de metodologías y estrategias que permitan cumplir su rol como promotor y entidad técnica responsable (ONAMIAP, 2018). Respecto a lo anterior, Castillo y Soria opinan lo siguiente:

El Estado -mediante sus instancias sectoriales y descentralizadas- debe promover y garantizar la activa participación de las mujeres en los procesos ligados a proyectos de industrias extractivas. Esta participación activa de las mujeres se debe de producir en los espacios de participación ciudadana exigidos por ley para cada fase de los

\footnotetext{
14 Artículo 5.-Para ser "comunero calificado" se requieren los siguientes requisitos: a) Ser comunero mayor de edad o tener capacidad civil; b) Tener residencia estable no menor de cinco años en la Comunidad; c) No pertenecer a otra Comunidad; d) Estar inscrito en el Padrón Comunal; y, e) Los demás que establezca el Estatuto de la Comunidad.

15 Se considera comunero integrado: a) Al varón o mujer que conforme pareja estable con un miembro de la Comunidad; y, b) Al varón o mujer, mayor de edad, que solicite ser admitido y sea aceptado por la Comunidad.

16 Artículo 6.

17 Artículo 11.4.
} 
proyectos extractivos (por ejemplo, talleres informativos y audiencias públicas) y en los mecanismos voluntarios (como monitoreos ambientales participativos) y en los procesos de negociación directa entre la población y la empresa (por ejemplo, acuerdos sobre distribución beneficios o creación de programas de empleo temporal) (Castillo y Soria, 2011, p. 13).

En el 2018, se creó la Comisión Sectorial para la Transversalización de los Enfoques de Género e Interculturalidad del Ministerio de Cultura, con el objetivo de "coordinar, articular, monitorear y fiscalizar la incorporación de los enfoques de género e interculturalidad en las políticas y gestión del sector Cultura, a fin de promover el cierre de brechas de género y la igualdad entre mujeres y hombres, y contribuir a la construcción de un Estado que garantice el principio de igualdad y los derechos de todas las personas y diversidad de grupos étnico-culturales"18 (El Peruano, 2018, p. 1). En articulación con el Ministerio de Cultura, sus funciones consisten en implementar "normas, directivas, lineamientos y demás instrumentos de gestión pública; acciones de seguimiento, evaluación y difusión; y generar informes de los avances y resultados de la participación de las mujeres" (ONAMIAP, 2019, p. 64).

Sin embargo, en la realidad, las referencias normativas no han conseguido formular medidas específicas y eficientes para fomentar la participación de mujeres comuneras y verificar que dicha participación sea tomada en cuenta en el proceso de consulta. Más allá de la mención del enfoque de género en reglamentos y guías, las referencias resultan ser fundamentalmente declarativas (ONAMIAP, 2019, p. 60), ya que las metodologías y estrategias institucionales orientadas a reformar la situación y verificar el cumplimiento de la participación son ausentes (ONAMIAP, 2019). Las mismas mujeres dan a entender que "(...) la metodología implementada no muestra esfuerzos de diálogo intercultural y de género" (ONAMIAP, 2019, 49), sino que, más bien, se da en el marco de diálogos verticales, metodologías demasiado técnicas y documentos poco amigables para su comprensión (ONAMIAP, 2018, p. 9). Estas falencias han llevado a una participación promedio baja $\mathrm{y}$, en algunos casos, prácticamente invisible, que no se mantiene y declina en la etapa del diálogo, que resulta ser una de las más decisivas de la consulta (ONAMIAP, 2018, p. 17). Esto lleva a la siguiente cuestión: ¿qué factores desalientan a las mujeres comuneras a participar en las etapas del proceso de consulta?

\section{Afectaciones y discriminación diferenciada hacia mujeres comuneras}

El Informe sobre Vulneraciones Diferenciadas a los Derechos Humanos de las Mujeres Indígenas en Contextos de Actividades Extractivas elaborado por la Coordinadora Nacional de Derechos Humanos, del 2016, evidencia cómo la "intersección o superposición de la matriz discriminatoria racial con la matriz discriminatoria

18 Artículo 1. 
de género hace a las mujeres indígenas un grupo particularmente vulnerable" (CNDDHH, 2016, p. 8). Las mujeres comuneras se encuentran especialmente expuestas a un tipo de discriminación transversal "por el hecho de ser mujeres, de ser campesinas, quechua hablantes y además por ser pobres" (Cuadros, p. 220 en CEPES, 2011). Esta discriminación puede provenir de otros comuneros varones, tanto como de agentes del Estado. Julia Cuadros relata que en la comunidad de Las Bambas "los varones ponen trabas a la participación de la mujer con el pretexto de que «van a hacerles quedar mal» porque ellas no saben y no quieren aprender" (Cuadros, p. 228 en CEPES, 2011). Al mismo tiempo, en espacios públicos o en la esfera social-comunal-política, las autoridades estatales, funcionarios de empresa mineras y representantes de federaciones campesinas reproducen la discriminación al impedir a las mujeres "hablar en público, realizar una gestión, un reclamo o acceder a cargos directivos (Cuadros, p. 228 en CEPES, 2011)" y "tampoco hay un cuidado por sancionar prácticas discriminatorias hacia las y los representantes indígenas" (ONAMIAP, 2018, p. 10). Las limitaciones en la participación se acentúan sobre todo cuando se trata de gestiones fuera de la comunidad, pues las mujeres comuneras "no se sienten a gusto al dirigirse en castellano, cara a cara, a un hombre desconocido" (Belaúnde, p. 169 en CEPES, 2011).

Silva-Santisteban (2017) explica que la tarea de la representación en las mesas de diálogo es considerada una tradición masculina, justificada por los varones al señalar que las mujeres "no quieren participar" y se estigmatiza su actividad en la representación, tildándolas como "rebeldes" e "indomables", mientras que se les exige priorizar sus tareas domésticas antes de participar en una movilización o asamblea. En la práctica, en las luchas, movilizaciones y mesas de diálogo se ven reflejadas, nuevamente, estas nociones sobre los roles de género, al relegar a las mujeres, en gran medida, las "pequeñas tareas", como la preparación de ollas de comida colectivas, elaboración de pancartas y arengas, en contraste con las tareas masculinas, que resaltan por su alto nivel de representación y dirigencia (Silva-Santisteban, 2017).

Su participación se ve debilitada, a su vez, por barreras socio educativas, tales como la dificultad de comunicarse en español cuando son monolingües (de sus lenguas nativas) y de comprender procesos lejanos a su realidad como los procesos técnicos que implica la actividad minera (ONAMIAP, 2016, p. 130). Además, condiciones culturales como los roles tradicionales de cuidado y alimentación, que limitan su tiempo para actividades de representación, no son tomadas en cuenta por las entidades encargadas de convocar los procesos de consulta previa (ONAMIAP, 2018, p. 8). Otros factores son la poca experiencia de participación en espacios públicos, sobre todo cuando se trata de ámbitos con "modalidades de participación diferentes a las pautadas culturalmente" al interior de su comunidad (ONAMIAP, 2019 , p. 43); la demanda de tiempo que suponen los hijos e hijas $(2019$, p. 43) y el carácter demasiado técnico de los talleres que resultan difíciles de comprender sin información previa $(2019$, p. 45). 
Esta situación responde a que "las estructuras políticas para la participación indígena están culturalmente predeterminadas y favorecen el lenguaje hegemónico de los hombres criollos y mestizos" (Belaúnde, p. 196 en CEPES, 2011). A su vez, muchas conversaciones que se establecen entre las comunidades campesinas y las industrias extractivas se plantean en términos de hombre a hombre (Silva-Santisteban, 2017). El machismo constituye un elemento que conecta a los hombres blancos, mineros, urbanos y profesionales con hombres ronderos, campesinos o apus de pueblos indígenas; consecuentemente, se establece "un pacto desigual entre élites masculinas colonizadoras y los hombres de los pueblos a los que se buscaba colonizar" (De Assis Climaco, 2017, p. 9 en Silva-Santisteban, 2017, pp. 14-15). La representación femenina, por lo tanto, se desarrolla en medio de una arena de negociaciones masculinas.

La predominante representación masculina en los espacios de negociación implica una subrepresentación de las demandas hechas desde la mirada femenina sobre el manejo de la tierra. Debido a los roles de género dentro de la comunidad, las mujeres comuneras poseen una mirada particular sobre el manejo de los recursos, "tienen mayor claridad sobre las necesidades de sus familias y sus comunidades, y [sobre] sus análisis costo-beneficio con respecto a la seguridad y soberanía alimentaria ${ }^{19}$, a la salud, conservación de los conocimientos tradicionales, equilibrio del medio ambiente, efectos del cambio climático, etc" (ONAMIAP, 2016, p. 129). Su vínculo con la naturaleza y la comunidad, su responsabilidad por la subsistencia y el territorio en el presente y el futuro las lleva a expresar preocupaciones de largo plazo sobre los impactos de una industria extractiva sobre la comunidad (ONAMIAP, 2018). De la misma forma, el rol productivo y proveedor de los hombres comuneros y la necesidad de generar ingresos para la subsistencia familiar les hace priorizar el corto plazo (ONAMIAP, 2018). Silva Santisteban describe esta situación como una "ontología diferenciada mujer/varón en torno al tema del territorio: para el hombre la lucha es ganar ese pedazo de tierra y poseerla; para la mujer es sentirla y vivirla" (SilvaSantisteban, 2017, p. 33). Es fundamental que las mujeres participen en todas las etapas de la consulta, pues su mirada largoplacista es tanto crucial como complementaria a la mirada masculina sobre los recursos de la comunidad. Teniendo esto en cuenta, es importante cuestionarse por qué los representantes de empresas mineras prefieren negociar con los hombres más que con las mujeres (Silva-Santisteban, 2017).

\section{¿Derecho consuetudinario o enfoque de género?}

Queda claro, entonces, que las brechas de género en la representación política durante procesos de consulta previa están condicionadas por estructuras, creencias y prácticas culturales; pero exacerbadas por una serie de vacíos legales y metodológicos que no

\footnotetext{
19 El término "soberanía alimentaria" hace referencia al derecho de los pueblos indígenas de administrar y producir sus alimentos de acuerdo a sus tradiciones y voluntad. Desde una perspectiva de género, las mujeres son, en gran medida, las responsables de garantizar la soberanía alimentaria dentro de sus comunidades.
} 
son cubiertos a cabalidad por las entidades estatales responsables. Estos vacíos legales y metodológicos también son identificados para la implementación eficaz de un enfoque de género en el la Ley N 29785 , en su Reglamento, en la Comisión Sectorial para la Transversalización de los Enfoques de Género e Interculturalidad e, incluso, en la Ley General de Comunidades Campesinas, donde el Estado se compromete a respetar la participación, servicios y trabajo de los comuneros, "regulado por un derecho consuetudinario autóctono". El conflicto se encuentra, justamente, en que el respeto por los usos y costumbres "implica reforzar la discriminación de la mujer en el acceso a las decisiones sobre la tierra en la comunidad" (Urrutia, 2007, p. 281), pues su derecho a la participación efectiva se enfrenta a formas consuetudinarias de participación comunal y a las estructuras de género tradicionales. En este punto emergen discusiones sobre cómo implementar una consulta previa, donde, supuestamente, se garantiza la participación de las comunidades campesinas, cuando, de acuerdo con sus usos y tradiciones, solo se incluye a los comuneros calificados. Entonces, frente a ello, surge la siguiente cuestión: ¿los derechos individuales de las mujeres a no ser discriminadas deben imponerse a derechos colectivos?

En ocasiones, el discurso del relativismo cultural y la multiculturalidad ha servido para "tolerar las violaciones a los derechos humanos o justificar la violencia de género arguyendo que se trata de costumbres tradicionales" (Cuadros, p. 266 en CEPES, 2011). De acuerdo con Zardo, a pesar de que el enfoque de género podría considerarse como una mera imposición foránea, en realidad constituye una directriz de los derechos humanos homogeneizar un mínimo estándar de respeto por cada ser humano ${ }^{20}$ (Zardo, 2013). Por lo tanto, "los estándares mínimos de equidad de género que concebimos como fundamentales en la comunidad internacional deberían ser aplicados con la misma fuerza en las prácticas culturales de cualquier comunidad indígena $^{21}$ (Zardo, 2013, p. 1057). Es aquí donde las políticas de interculturalidad cumplen un rol fundamental: conciliar las esferas del derecho individual y del derecho colectivo, por medio de un diálogo intercultural que incorpore el entendimiento de lo femenino en los procesos de consulta (Hoyos y Valencia, 2017, p. 16). La situación de discriminación y racismo, acentuada por las estructuras patriarcales, crean una realidad sumamente compleja de abordar, que amerita integrar la perspectiva de género con la de las comunidades campesinas, implementar mecanismos de monitoreo de la participación de mujeres y explorar las relaciones de poder entre comuneros y comuneras para implementar políticas públicas eficientes (CEPAL, 2014, p. 30). Como menciona Julia Cuadros:

La responsabilidad de incorporar las necesidades e intereses de las mujeres en el proceso para que estas se beneficien equitativamente de los beneficios que reportaría la actividad minera, no debiera depender únicamente del esfuerzo que realicen las mismas mujeres, que se organizan para hacer conocer sus demandas; sino que también

\footnotetext{
20 Mi traducción.

21 Mi traducción.
} 
es responsabilidad de las organizaciones comunales a fin de incorporar en sus planes de desarrollo comunitario las necesidades e intereses de las mujeres; así como también es responsabilidad de los gobiernos locales y de las empresas mineras (Cuadros, 2010b, p. 2).

Por ello, el reto está en incentivar reformas en las políticas públicas, así como en las prácticas y comportamientos concretos de un conjunto de actores, tales como "autoridades y funcionarios de los gobiernos, locales, regionales y nacional, organismos públicos, empresas privadas, organismos no gubernamentales, cooperación internacional" (Cuadros, 2010a, p. 7). Es importante que estas acciones tengan un objetivo de largo plazo, que empoderen a las mujeres como colectivo y no solo como individualidades; y que esto vaya de la mano con el empoderamiento económico, facilitando el acceso a créditos, recursos, a su manejo y administración (CEPAL, 2014). Asimismo, es necesario "mejorar la articulación entre las entidades del aparato estatal a cargo, tanto de lo temas de género, como de los pueblos indígenas, para delinear una agenda de la mujer y de género con las propias mujeres" (CEPAL, 2014, p. 27).

"Es una pre condición para lograr la igualdad entre hombres y mujeres" la alteración total de las estructuras y procesos que reproducen la posición subordinada de la mujer (Bórquez, p. 64 en CEPES, 2011) y empoderar a la mujer comunera; esto es: aumentar su cuota de poder, de negociación y participación política en las esferas públicas y privadas, en los espacios intra comunales y extra comunales. Sin embargo, para que estas intervenciones tengan un alcance real, es necesario sensibilizar y capacitar a los varones, con el fin de lograr cambios en sus prácticas cotidianas que vayan más allá del mero respeto a la ley (Cuadros, p. 220 en CEPES, 2011). Este cambio, sin duda, implica una reforma en las referencias normativas de la Ley 29785 de la consulta previa, y, del mismo modo, las organizaciones indígenas deben actualizar sus estatutos comunales para facilitar el reconocimiento de las mujeres como comuneras calificadas para la participación y tenencia de tierras, e implementar acciones afirmativas para alentarlas a asumir cargos directivos y de representación comunal y extra comunal (ONAMIAP, 2018, p. 24).

\section{Conclusiones}

A partir de la información analizada, se pueden desplegar algunas conclusiones. Primero, en los procesos de negociación con industrias extractivas, las mujeres comuneras se encuentran especialmente vulnerables ser discriminadas por el hecho de ser mujeres, campesinas y quechua hablantes. Las brechas en la participación de mujeres comuneras se ven acentuadas por vacíos legales en las referencias normativas. El respeto por la autonomía política de las comunidades campesinas entra en conflicto con la implementación de una metodología con enfoque de género, en tanto la participación de las mujeres queda condicionada a los usos y tradiciones, cuyas estructuras de poder y de género, en la práctica, no reflejan una participación 
política paritaria. Estas limitaciones del derecho formal y consuetudinario permiten apreciar las múltiples dimensiones de las trabas que impiden a las mujeres comuneras asumir roles de liderazgo, participación y negociación política. Cabe cuestionarnos, entonces, si este instrumento de desarrollo está empoderando a la mujer comunera como individuo, o si, más bien, es un proceso que acentúa los roles de políticos y de género tradicionales.

Luego, la ausencia de medidas concretas por parte del Viceministerio de Interculturalidad supone la necesidad de revisar y replantear las estrategias y metodologías orientadas a la aplicación de un enfoque de género efectivo en los procesos de consulta. Es aquí donde las políticas de interculturalidad cumplen un rol fundamental: lograr una metodología intercultural que consiga conciliar el derecho a la equidad y el derecho consuetudinario de las comunidades campesinas, por medio de un diálogo que incorpore el entendimiento de los roles de género y explore las relaciones de poder entre comuneros y comuneras.A pesar de que, desde el relativismo cultural, la exigencia de incorporar el enfoque de género podría considerarse una imposición ajena a las las tradiciones consuetudinarias, en realidad constituye un derecho humano el garantizar una cuota de paridad de género en los procesos políticos que incumben a la comunidad campesina en su totalidad. Por lo tanto, queda vigente el reto de reformular las normativas legales de la Ley $\mathrm{N}^{\circ} 29785$ y los estatutos de las comunidades campesinas para lograr un estándar de equidad de género, de la mano con la capacitación y sensibilización de los comuneros varones para modificar las prácticas que reproduzcan las brechas en la participación.

Estas reflexiones recalcan la urgente necesidad de empoderar a las mujeres comuneras e incrementar su cuota de poder, negociación y liderazgo en las esferas intra y extra comunales, pues poseen una mirada particular. respecto a los impactos de la industria extractiva en los recursos de la comunidad; $y$, en tanto su inclusión supone una representación legítima de las demandas de los pueblos indígenas y como una reivindicación del liderazgo femenino sobre la protección de la tierra y la naturaleza. Finalmente, aún queda necesario resolver, a profundidad y en futuras investigaciones, las siguientes preguntas: ¿cómo las comunidades interpretan las referencias legales sobre la consulta previa? ¿Cómo se logran conciliar las esferas del derecho consuetudinario, en las comunidades, y de los derechos individuales desde las instituciones del gobierno? ¿De qué manera se podría empoderar a la mujer en el ámbito público comunal? 


\section{Referencias bibliográficas}

Asociación Madre Coraje. (2005). Desarrollo Rural con Equidad. Lima: Biblioteca Nacional del Perú. Recuperado de: https://www.madrecoraje.org/wp-content/uploads/2017/02/ desarrollo-rural-equidad.pdf

Belaúnde, L. (2011). "La mujer indígena en la colonización amazónica: ruptura de la masculinidad, tránsitos y nuevos espacios políticos”. Mujer Rural: Cambios y Persistencias en América Latina. Lima: Centro Peruano de Estudios Sociales - CEPES. (pp. 181-206). Recuperado de:

https://biblio.flacsoandes.edu.ec/libros/digital/55681.pdf

Bórquez, R. (2011) "Mujeres indígenas, campesinas y su organización por el acceso a la tierra". Mujer Rural: Cambios y Persistencias en América Latina. Lima: Centro Peruano de Estudios Sociales - CEPES. Pp. 59-84. Recuperado de: https://biblio.flacsoandes.edu.ec/ libros/digital/55681.pdf

Centro Amazónico de Antropología y Aplicación Práctica (CAAAP). (2017). ¿Cómo Va La Aplicación De La Consulta Previa Centro Amazónico De Antropología Y Aplicación Práctica En El Perú?: Avances Y Retos. Lima: Biblioteca Nacional del Perú. Recuperado de: http://www.caaap.org.pe/2017/documentos/ConsultaPrevia_CAAAP_2daEd_2017.pdf

Comisión Económica para América Latina y el Caribe (CEPAL). (2014). Mujeres Indígenas: nuevas protagonistas para nuevas politicas. Naciones Unidas CEPAL.Recuperado de:

https://www.cepal.org/es/publicaciones/36779-mujeres-indigenas-nuevas-protagonistasnuevas-politicas

Castillo, G. y Soria, L. (2011). Diagnóstico de justicia de género en los procesos de consulta de proyectos extractivos en Bolivia, Ecuador y Perú. Lima: OXFAM y Societas Consultora de Análisis Social. Recuperado de: https:/www.academia.edu/1215068/Diagn\%C3\%B3stico_ de_justicia_de_g\%C3\%A9nero_en_los_procesos_de_consulta_de_proyectos_extractivos_ en_Bolivia_Ecuador_y_el_Per\% $\%$ C $3 \%$ BA

Coordinadora Nacional de Derechos Humanos. (2016). Informe sobre Vulneraciones Diferenciadas a los Derechos Humanos de las Mujeres Indígenas en Contextos de Actividades Extractivas en el Perú. Lima. Recuperado de:

https://uprdoc.ohchr.org/uprweb/downloadfile.aspx?filename=4509\&file=Annexe7

Congreso de la República. (1992). Ley General de Comunidades Campesinas. Lima. Recuperado de:

h t t p ://www 2.congreso.gob.pe/si cr/cendocbib/con 3 _uibd.ns f/ 1DAB0BF2E43B8FBB0525797B006DE3C0/\%24FILE/1_LEY_24656_Ley_General_ Comunidades_Campesinas_SPIJ.pdf

Congreso de la República. (2019). Ley del Derecho a la Consulta Previa a los Pueblos Indígenas u Originarios, reconocido en el Convenio 169 de la Organización Internacional del Trabajo (OIT). Lima. Recuperado de:

http://consultaprevia.cultura.gob.pe/wp-content/uploads/2014/11/Ley-N---29785-Leydel-derecho-a-la-consulta-previa-a-los-pueblos-ind--genas-originarios-reconocido-en-elConvenio-169-de-la-Organizacion-Internacional-del-Trabajo-OIT.pdf 
Cuadros, J. (2010a). Impacto de la minería en la vida de hombres y mujeres en el sur andino. Lima: Cooperación - Acción Solidaria para el desarrollo. Recuperado de: http://cooperaccion. org.pe/publicaciones/impactos-de-la-mineria-en-la-vida-de-hombres-y-mujeres-en-el-surandino-una-mirada-desde-el-genero-y-la-interculturalidad-los-casos-las-bambas-y-tintaya/

Cuadros, J. (2010b). Impactos de la minería en la vida de hombres y mujeres. Género y Minería: Transformaciones del poder y alternativas al desarrollo. Recuperado de:

https:/generoymineriaperu.files.wordpress.com/2013/05/artc3adculo-jcf-gc3a9nero-yminerc3ada.pdf

Cuadros, J. (2011). "Impactos de la minería en la vida de hombres y mujeres del sur andino. Los casos Las Bambas y Tintaya". Mujer Rural: Cambios y Persistencias en América Latina. Lima: Centro Peruano de Estudios Sociales - CEPES. Pp. 207-238. Recuperado de: https://biblio.flacsoandes.edu.ec/libros/digital/55681.pdf

Diez, A. (2011). “Tres utopías sobre la propiedad femenina (absoluta) de la tierra. Reflexiones a partir del acceso de mujeres campesinas a tierras comunales en Huancavelica”. Mujer Rural: Cambios y Persistencias en América Latina. Lima: Centro Peruano de Estudios Sociales CEPES. Pp. 85-116. Recuperado de:

https://biblio.flacsoandes.edu.ec/libros/digital/55681.pdf

El Peruano. (2018). Crean la Comisión Sectorial para la transversalización de los enfoques de género e Interculturalidad. Recuperado de:

https://busquedas.elperuano.pe/normaslegales/crean-la-comision-sectorial-para-latransversalizacion-de-lo-resolucion-ministerial-n-352-2018-mc-1686447-1/

El Peruano. (2012). Reglamento de la Ley $N^{o} 29785$, Ley del Derecho a la Consulta Previa a los Pueblos Indígenas u Originarios reconocido en el Convenio 169 de la Organización Internacional del Trabajo (OIT). Lima. Recuperado de:

https://sinia.minam.gob.pe/normas/reglamento-ley-derecho-consulta-previa-pueblosindigenas-originarios

Hoyos, M. y Valencia, L. (2017). Participación de la mujer indígena en la consulta previa en el resguardo indígena Alto del Rey. Santiago de Cali: Pontificia Universidad Javeriana de Cali. Recuperado de:

http://vitela.javerianacali.edu.co/handle/11522/10184

Ministerio de Cultura. (2016). Derecho a la Consulta Previa: Derechos Colectivos De Los Pueblos Indígenas U Originarios. Recuperado de:

Ministerio de Justicia. (2014) Convención Sobre La Eliminación De Todas Las Formas De Discriminación Contra La Mujer. Lima: Biblioteca Nacional del Perú. Recuperado de: http://www.mimp.gob.pe/files/direcciones/dgfc/diff/iiv/sistemauniversal_onu/6_ ResolucionLegislativa_23432_CEDAW.pdf

OIT (Organización Internacional del Trabajo). (2014). Convenio Núm. 169 de la OIT sobre Pueblos Indígenas y Tribales. Recuperado de:

https://www.ilo.org/wcmsp5/groups/public/---americas/---ro-lima/documents/publication/ wcms_345065.pdf 
Organización Nacional de Mujeres Indígenas Andinas y Amazónicas del Perú (ONAMIAP). (2016). Consulta previa en minería: Manual De Capacitación Para Mujeres Indígenas. Lima: Biblioteca Nacional del Perú. Recuperado de:

http://www.consulta-previa.org.pe/publicaciones/Manual_de_capacitacion_para_mujeres_ web.pdf

Organización Nacional de Mujeres Indígenas Andinas y Amazónicas del Perú (ONAMIAP). (2018). Consulta Previa: Una Demanda de las Mujeres Indígenas en el Perú. Lima: Boletín ONAMIAP. Recuperado de:

http://onamiap.org/publicacion/consulta-previa-una-demanda-de-las-mujeres-indigenas-delperu/

Organización Nacional de Mujeres Indígenas Andinas y Amazónicas del Perú (ONAMIAP). (2019). ¡Sin mujeres indígenas, no! Aproximaciones desde la implementación de la consulta previa en la industria extractiva en el Perú. Lima: Tarea Asociación Gráfica Educativa. Recuperado de: https://cng-cdn.oxfam.org/peru.oxfam.org/s3fs-public/file_attachments/ Sin_mujeres_indigenas_no.pdf

Silva-Santisteban, R. (2017). Mujeres y conflictos ecoterritoriales. Impactos, estrategias, resistencias. Lima: CMP Flora Tristán. Recuperado de: https://www.demus.org.pe/wpcontent/uploads/2018/02/Mujeresyconflictos_Convenio.-2017.pdf

Urrutia, J. (2017). “Los estudios sobre comunidades y la perspectiva de género”. ¿Qué sabemos de las comunidades campesinas?. Lima: Allpa. Recuperado de:

http://www.scielo.org.pe/scielo.php?script=sci_arttext\&pid=S0254-92122013000100009

Zardo, M. (2013). “Gender Equality and Indigenous Peoples' Right to Self-Determination and Culture". American University International Law Review. Volúmen 28, No 4, pp. 10531090. Recuperado de:

https://digitalcommons.wcl.american.edu/auilr/vol28/iss4/6/ 